Cite this: Org. Biomol. Chem., 2014, 12,5082

Received 7th May 2014, Accepted 23rd May 2014

DOI: $10.1039 / c 40 b 00945 b$

www.rsc.org/obc

\section{Iron-catalysed, general and operationally simple formal hydrogenation using $\mathrm{Fe}(\mathrm{OTf})_{3}$ and $\mathrm{NaBH}_{4}+\dagger$}

\author{
Alistair J. MacNair, ${ }^{a}$ Ming-Ming Tran, ${ }^{a}$ Jennifer E. Nelson, ${ }^{a}$ G. Usherwood Sloan, ${ }^{a}$ \\ Alan Ironmonger ${ }^{\mathrm{b}}$ and Stephen P. Thomas*a
}

An operationally simple and environmentally benign formal hydrogenation protocol has been developed using highly abundant iron (III) salts and an inexpensive, bench stable, stoichiometric reductant, $\mathrm{NaBH}_{4}$, in ethanol, under ambient conditions. This reaction has been applied to the reduction of terminal alkenes (22 examples, up to $95 \%$ yield) and nitro-groups (26 examples, up to $95 \%$ yield). Deuterium labelling studies indicate that this reaction proceeds via an ionic rather than radical mechanism.

\section{Introduction}

The hydrogenation of apolar and polar functionalities is routine in both academia and industry for the production of fine and bulk chemicals. ${ }^{1}$ Highly operationally simple hydrogenation methods using heterogeneous (e.g. $\left.\mathrm{Pd} / \mathrm{C}-\mathrm{H}_{2}\right)$ or homogeneous (e.g. $\left.\mathrm{Ru} / \mathrm{NEt}_{3}-\mathrm{HCO}_{2} \mathrm{H}\right)$ systems have allowed the broadest possible user base to exploit this reaction. ${ }^{2}$ To date, the most commonly used methods require precious or semi-precious transition metal complexes or finely divided powders. ${ }^{1}$

Iron-based catalysts offer several advantages over more traditional 'noble' metal systems due to the high abundance, long-term availability, ${ }^{3}$ low cost and low toxicity of iron. ${ }^{4}$ On an industrial scale, heterogeneous iron catalysts have been widely exploited; however the use of soluble iron catalysts is considerably less well developed. ${ }^{5}$

Iron-catalysed alkene reductions have been reported however many systems suffer from the need for: elevated temperatures; high hydrogen pressure; chemical activation or are superstoichiometric in iron. ${ }^{6}$ Although several well defined

${ }^{a}$ School of Chemistry, University of Edinburgh, Joseph Black Building, West Mains Road, Edinburgh EH9 3JJ, UK. E-mail: stephen.thomas@ed.ac.uk;

Fax: +44 (0)131650 6453

${ }^{b}$ Research and Development, GlaxoSmithKline, Gunnelswood Road, Stevenage SG1 $2 N Y, U K$

†We dedicated this paper to Dr Stuart Warren on the occasion of his 75th birthday.

\$Electronic supplementary information (ESI) available. See DOI: 10.1039/ c4ob00945b and highly active homogeneous iron complexes for catalytic hydrogenation have been developed, ${ }^{7}$ notably by Chirik, ${ }^{8}$ these catalysts and pre-catalysts are highly air- and moisture-sensitive, so have not seen widespread adoption. On a small scale, the use of hydrogen gas has numerous drawbacks, particularly with safe storage and handling. These can be circumvented by the use of an inexpensive, bench-stable, solid hydrogen source. $\mathrm{NaBH}_{4}$ is air- and moisture stable and produced on kilotonne scale annually. ${ }^{9}$

Ashby used $\mathrm{LiAlH}_{4}$ in conjunction with stoichiometric amounts of transition metal halides, including $\mathrm{FeCl}_{3}$ and $\mathrm{FeCl}_{2}$, to reduce 1-octene. ${ }^{10}$ Kano reported a biomimetic reduction of styrene derivatives using an iron-porphinato complex and $\mathrm{NaBH}_{4}$ however reductive homocoupling of radical species was a major side-reaction. ${ }^{11}$ Recently, Boger reported the hydrofunctionalisation of alkenes mediated by superstoichiometric iron(III) salts and $\mathrm{NaBH}_{4} \cdot{ }^{12}$ In the absence of an electrophile, it was found that tertiary alkenes were hydrogenated (Scheme 1). ${ }^{12 a}$

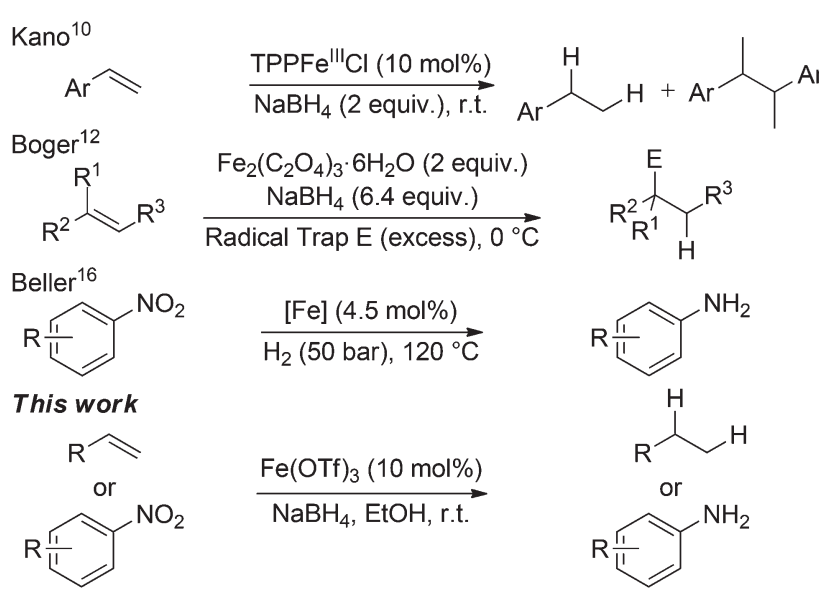

Scheme 1 Iron-catalysed reductions and reductive functionalisations. TTP = tetraphenylporphyrinato. $[\mathrm{Fe}]=$ iron phenanthroline complex pyrolysed onto a carbon support. 
Along with alkene hydrogenation, the reduction of nitroarenes to aniline derivatives represent another high-value industrial process for the preparation of a wide range of synthetic precursors, including; dyes, pharmaceuticals, agrochemicals and polymers. ${ }^{13}$ Iron-catalysed hydrogenation of nitroarenes is well established using iron(0) carbonyl precursors acting via a cohort of in situ generated iron species. ${ }^{14}$ Beller has developed a number of homogeneous iron-catalysed nitroarene reductions ${ }^{15}$ and recently carbon-supported heterogeneous systems using either $\mathrm{N}_{2} \mathrm{H}_{4} \cdot 6 \mathrm{H}_{2} \mathrm{O}$ or $\mathrm{H}_{2}$ as the stoichiometric reductant (Scheme 1). ${ }^{16}$

$\mathrm{NaBH}_{4}$ is a poor reducing agent for nitro-groups under ambient conditions, although it has been used in the presence of palladium, nickel, copper catalysts for the reduction of nitro-groups to amines. ${ }^{17}$ Additionally, Sakaki and co-workers have reported the use of $\mathrm{NaBH}_{4}$ and porphyrinatoiron complexes for the reduction of a limited number of nitroarenes. ${ }^{18}$

Herein we report an iron-catalysed, $\mathrm{NaBH}_{4}$-mediated reduction procedure that is capable of reducing both alkene and nitroarene functionalities.

\section{Results and discussion}

Alkene reduction was first investigated and successful 'hydrogenation' of 4-phenyl-1-butene $\mathbf{1 a}$, to the alkane $\mathbf{2 a}$, was found using stoichiometric (Table 1, entries 1-4) and substoichiometric (entries 5-10) amounts of simple, commercially available, iron salts in the presence of $\mathrm{NaBH}_{4} \cdot{ }^{19}$

Iron(III) chloride, bromide and triflate supported the reduction (entries 1-4); however when stoichiometric $\mathrm{FeCl}_{3}$ or

Table 1 Initial screen of activity of iron salts for the reduction of 4-phenyl-1-butene ${ }^{a}$

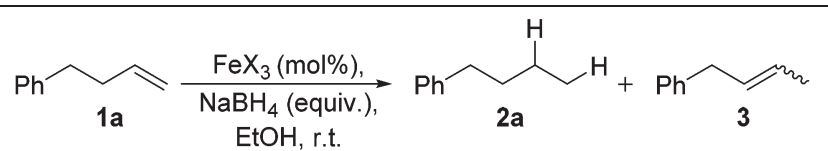

\begin{tabular}{|c|c|c|c|c|c|}
\hline \multirow[b]{2}{*}{ Entry } & \multirow[b]{2}{*}{$\mathrm{FeX}_{2 / 3}$} & \multirow[b]{2}{*}{$\begin{array}{l}\mathrm{FeX}_{2 / 3} \\
\left(\mathrm{~mol}_{0}\right)\end{array}$} & \multirow{2}{*}{$\begin{array}{l}\text { Equiv. } \\
\mathrm{NaBH}_{4}\end{array}$} & \multicolumn{2}{|c|}{ Yield $^{b}(\%)$} \\
\hline & & & & $2 \mathbf{a}$ & 3 \\
\hline 1 & $\mathrm{FeCl}_{3}$ & 100 & 2 & 15 & 2 \\
\hline 2 & $\mathrm{FeBr}_{3}$ & 100 & 2 & 42 & 1 \\
\hline 3 & $\mathrm{Fe}(\mathrm{OTf})_{3}$ & 100 & 1 & 19 & 3 \\
\hline 4 & $\mathrm{Fe}(\mathrm{OTf})_{3}$ & 100 & 2 & 91 & 9 \\
\hline 5 & $\mathrm{FeCl}_{3}$ & 10 & 2 & 91 & 5 \\
\hline 6 & $\mathrm{FeCl}_{3}{ }^{c}$ & 10 & 2 & 89 & 6 \\
\hline 7 & $\mathrm{Fe}(\mathrm{OTf})_{3}$ & 10 & 2 & 90 & 10 \\
\hline 8 & $\mathrm{Fe}(\mathbf{O T f})_{3}{ }^{d}$ & 10 & 1.5 & 90 & 10 \\
\hline 9 & $\mathrm{Fe}(\mathrm{OTf})_{3}{ }^{e}$ & 1 & 2 & 47 & 7 \\
\hline 10 & $\mathrm{Fe}(\mathrm{OTf})_{2}$ & 10 & 2 & 11 & 0 \\
\hline 11 & HOTf & 10 & 2 & 6 & 0 \\
\hline 12 & NaOTf & 10 & 2 & 4 & $0^{8}$ \\
\hline
\end{tabular}

${ }^{a}$ Conditions: $0.50 \mathrm{mmol}$ 4-phenyl-1-butene, $n$ mol\% iron(III) salt, $n$ equiv. $\mathrm{NaBH}_{4}$, EtOH $(2 \mathrm{ml})$, r.t., 16 h. ${ }^{b}$ Yield measured by ${ }^{1} \mathrm{H}$ NMR of the crude reaction product using 1,3,5-trimethoxybenzene as internal standard. ${ }^{c}>99.99 \%$ purity. ${ }^{d} 6$ h. ${ }^{e} 48$ h. ${ }^{f} 75 \%$ starting material recovered. ${ }^{g} 80 \%$ starting material recovered.

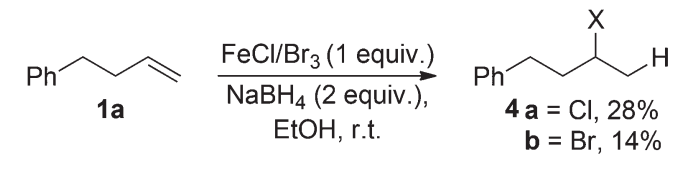

Scheme 2 Formation of halogenated side products, $\mathrm{X}=\mathrm{Cl} / \mathrm{Br}$.

$\mathrm{FeBr}_{3}$ were used, (3-chlorobutyl)benzene $\mathbf{4 a}$ and (3-bromobutyl)benzene $\mathbf{4 b}$ were obtained as side-products respectively. This was presumably as a result of radical formation, followed by halide abstraction from the iron salt (Scheme 2). ${ }^{20}$

Use of $\mathrm{Fe}(\mathrm{OTf})_{3}$ prevented the halogenation reaction and in addition, it was found that $\mathrm{Fe}(\mathrm{OTf})_{3}$ gave the shortest reaction times. ${ }^{21}$ At a $10 \mathrm{~mol} \%$ iron loading, the quantity of $\mathrm{NaBH}_{4}$ could be lowered to 1.5 equivalents and the reaction time reduced to 6 hours, without decreasing reaction yield (entry 8), however in all cases, it was found the some isomerisation to the internal alkene 3 was observed. An attempt to reduce the catalyst loading to $1 \mathrm{~mol} \%$ gave considerably diminished yields, even after $48 \mathrm{~h}$ (entry 9).

The catalytic activity of iron was attested to by high purity $\mathrm{FeCl}_{3}(>99.99 \%$ ) showing equal catalytic activity (entry 6) to the reagent grade salts. ${ }^{22}$ Additionally in the absence of iron, no reduction of the alkene was observed: triflic acid and sodium triflate (entries 11 and 12) were not catalytically active; only the starting material 1a was recovered.

Presumably due to the high solubility of $\mathrm{NaBH}_{4}$ in these solvents, successful reduction reactions were achieved in methanol, 1-butanol, 2-butanol and acetonitrile, however the highest yields were obtained in ethanol. ${ }^{19}$ Along with the sustainability and low toxicity of ethanol, makes it the favoured reaction solvent.

With the optimal conditions of $\mathrm{Fe}(\mathrm{OTf})_{3}(10 \mathrm{~mol} \%), \mathrm{NaBH}_{4}$ (150 $\mathrm{mol} \%$ ) in ethanol, the substrate scope of the formal hydrogenation was investigated. The developed system was found to be chemoselective for the reduction of terminal alkenes (Table 2). Reductions in the presence of aryl halides showed no protodehalogenation ${ }^{23}$ except in the case of aryl bromide 1d where $18 \%$ of the protodehalogenated product was observed (Table 2, entries 2-4).

Despite previous reports of the reduction of esters and amides with $\mathrm{NaBH}_{4}$ in $\mathrm{MeOH},{ }^{24}$ chemoselective alkene reduction was observed for substrates being both ester and amide functionalities (entries 6-8). Although a carboxylic acid functionalised substrate was poorly tolerated (entry 5), reduction of 4-phenyl-1-butene $\mathbf{1 a}$ in the presence of acetic acid, using excess $\mathrm{NaBH}_{4}$, was successful. Despite the lability of benzyl protecting groups under conventional hydrogenation conditions, both benzyl and silyl ethers were conserved during alkene reduction (entries 9 and 10).

Although the reduction was carried out in ethanol, inclusion of an alcohol or ketone in the alkene substrate diminished reduction yields (entries 12 and 13). Styrene derivatives were successfully reduced; however longer reaction times and higher quantities of $\mathrm{NaBH}_{4}$ were required and yields were generally lower than the alkyl analogues (entries 14-17). 
Table 2 Scope and limitation of the iron-catalysed, hydride-mediated reduction ${ }^{a}$

\begin{tabular}{|c|c|}
\hline & $\mathrm{Fe}(\mathrm{OTf})_{3}(10 \mathrm{~mol} \%)$ \\
\hline 1a-v & $\begin{array}{c}\mathrm{NaBH}_{4}, \mathrm{EtOH} \\
\text { r.t., } 6 \mathrm{~h}\end{array}$ \\
\hline
\end{tabular}

Entry Substrate

$\mathrm{R}=\mathrm{OH}(\mathbf{1 e})$

$\mathrm{R}=\mathrm{OMe}(\mathbf{1 f})$

$\mathrm{R}=\mathrm{NH}^{t} \mathrm{Bu}(\mathbf{1 g})$

$R=-\xi \sum_{(1 h)}^{-\xi}$

9

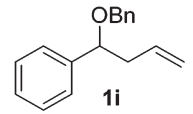

Product

Yield $^{b}(\%)$

6
7
8<smiles>CCCc1ccccc1</smiles><smiles>[R]c1ccc(CCCC)cc1</smiles><smiles>[R]C(=O)c1ccc(CCCC)cc1</smiles>

$92(79)$<smiles>C=CCC(OCC)c1ccccc1</smiles>

11<smiles>C=CCC1CCCCC1</smiles>

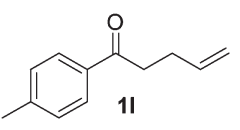

$$
\text { 2f }
$$

$2 \mathrm{~g}$

$\mathrm{OH}$<smiles>CCCC(OCc1ccccc1)c1ccccc1</smiles><smiles>CCCC(O[Na])c1ccccc1</smiles><smiles>CCCCC(O)c1ccc(C)cc1</smiles><smiles>CCc1cc[R]cc1</smiles>
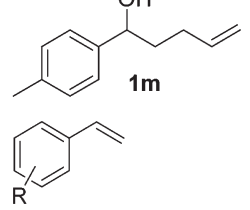

$2 n$
20
$2 p$

$\mathrm{R}=4-{ }^{-} \mathrm{Bu}(10)$

$\mathrm{R}=4-\mathrm{OMe}(\mathbf{1 p})$

$\mathrm{R}=3-\mathrm{CF}_{3}(\mathbf{1} \mathbf{q})$

${ }^{{ }^{B} u_{0}} \overbrace{1 \mathbf{r}}^{\mathrm{O}}$

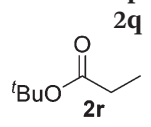

$58^{d}$

o

p

$55(45)^{d}$

$56(46)^{d}$

18
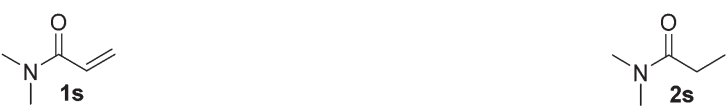<smiles>C/C=C/c1ccccc1</smiles><smiles>CCCc1ccccc1</smiles>

20<smiles>C=C(C)[C@H]1[CH]C=C(C)CC1</smiles><smiles>CC1=CCC(C(C)C)CC1</smiles><smiles>C#CCCCc1ccccc1</smiles><smiles>CCCCCc1ccccc1</smiles>

$7,34^{e}$

3

${ }^{a}$ Conditions: $1 \mathrm{mmol}$ alkene, $10 \mathrm{~mol} \% \mathrm{Fe}(\mathrm{OTf})_{3}$, EtOH $(4 \mathrm{ml}), 1.5$ equiv. $\mathrm{NaBH}_{4}$, r.t., 6 h. ${ }^{b}$ Determined by ${ }^{1} \mathrm{H}$ NMR using $1,3,5$-trimethoxybenzene as internal standard. Isolated yield in parentheses. ${ }^{c} 18 \%$ phenylbutane $2 \mathrm{a}$ also recovered. ${ }^{d}$ Conditions: $1 \mathrm{mmol}$ alkene, $10 \mathrm{~mol} \% \mathrm{Fe}(\mathrm{OTf})_{3}$, EtOH (4 ml), 2 equiv. $\mathrm{NaBH}_{4}$, r.t., 18 h. ${ }^{e} 20$ equiv. $\mathrm{NaBH}_{4}$. 
In contrast to the work of de Vries using iron nanoparticles, ${ }^{25}$ acrylate and acrylamide derivatives were chemoselectively reduced at the alkene (entries 18 and 19). The reaction was highly selective for the reduction of unsubstituted terminal alkenes; only trace reduction of $\beta$-methyl styrene 1 t was observed and neither the internal nor 1,1-disubstituted alkenes of (+)-limonene $\mathbf{1} \mathbf{u}$ underwent reduction (entries 20 and 21). ${ }^{26}$ Attempts to extend the reaction scope to the terminal alkyne; 5-phenyl-butyne $\mathbf{1 v}$, resulted in a poor yield of alkane, even with excess $\mathrm{NaBH}_{4}$ (entry 22). The reduction of 4phenyl-1-butene in the presence of $10 \mathrm{~mol} \%$ diphenylacetylene resulted in a reduced yield of phenylbutane (15\%) and no evidence of reduction of the diphenylacetylene.

During the development of the alkene 'hydrogenation', the reduction of the nitro-group of 3-nitrostyrene was observed to occur competitively with the reduction of the alkene. Using nitrobenzene as a model substrate, simple iron salts were investigated for catalytic activity in the reduction of the nitrogroup to primary amines. $\mathrm{FeCl}_{3}$ offers an inexpensive and readily available iron(III) source and good reactivity was found with increased $\mathrm{NaBH}_{4}$ loading (Table 3, entries 1-3). The use of high-purity $\mathrm{FeCl}_{3}(\geq 99.99 \%)$ again did not change the observed reactivity, (entry 4). However, returning to $\mathrm{Fe}(\mathrm{OTf})_{3}$ gave higher conversions to aniline (entry 6), and allowed reaction times to be reduced to $4 \mathrm{~h}$.

Even using the apparently more active salt, $\mathrm{Fe}(\mathrm{OTf})_{3}$, it was found that the quantity of $\mathrm{NaBH}_{4}$ could not be reduced without diminishing conversion to the product. In the absence of an iron salt, no reduction of nitrobenzene to aniline was observed, irrespective of the amount of $\mathrm{NaBH}_{4}$ used. Lewis acids; $\mathrm{BF}_{3}$ and $\mathrm{AlCl}_{3}$, were ineffective as catalysts (entries 10 and 11) and the use of triflic acid (entry 12) also resulted in only starting material being recovered.

Table 3 Optimisation of nitroarene reduction ${ }^{a}$

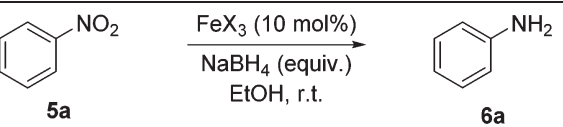

\begin{tabular}{|c|c|c|c|c|}
\hline Entry & $\mathrm{FeX}_{2 / 3}$ & $\mathrm{NaBH}_{4}$ equiv. & $t(\mathrm{~h})$ & Conversion $^{b}(\%)$ \\
\hline 1 & $\mathrm{FeCl}_{3}$ & 2 & 18 & 15 \\
\hline 2 & $\mathrm{FeCl}_{3}$ & 4 & 18 & 51 \\
\hline 3 & $\mathrm{FeCl}_{3}$ & 20 & 18 & 88 \\
\hline 4 & $\mathrm{FeCl}_{3}{ }^{c}$ & 20 & 18 & 90 \\
\hline 5 & $\mathrm{FeCl}_{2}$ & 20 & 18 & 62 \\
\hline 6 & $\mathrm{Fe}(\mathrm{OTf})_{2}$ & 20 & 18 & 60 \\
\hline 7 & $\mathrm{Fe}(\mathrm{OTf})_{3}$ & 20 & 18 & 99 \\
\hline 8 & $\mathrm{Fe}(\mathrm{OTf})_{3}$ & 10 & 18 & 32 \\
\hline 9 & $\mathrm{Fe}(\text { OTf })_{3}$ & 20 & 4 & 99 \\
\hline 10 & $\mathrm{BF}_{3} \cdot \mathrm{Et}_{2} \mathrm{O}$ & 20 & 4 & $0^{d}$ \\
\hline 11 & $\mathrm{AlCl}_{3}$ & 20 & 4 & $0^{e}$ \\
\hline 12 & HOTf & 20 & 4 & $1^{f}$ \\
\hline
\end{tabular}

${ }^{a}$ Conditions: $0.5 \mathrm{mmol}$ 4-phenyl-1-butene, $10 \mathrm{~mol} \%$ iron salt, $\mathrm{NaBH}_{4}$, ethanol $(4 \mathrm{ml})$, r.t. ${ }^{b}$ Conversion measured by ${ }^{1} \mathrm{H}$ NMR. ${ }^{c}>99.99 \%$ purity. ${ }^{d} 57 \%$ starting material recovered. ${ }^{e} 31 \%$ starting material recovered. ${ }^{f} 78 \%$ starting material recovered.
Using these conditions, substrate scope was investigated. $o-, m^{-}, p$-Methyl nitrobenzene, and even the sterically hindered 2,6-dimethyl nitrobenzene were all successfully reduced (Table 4, entries 2-5). Nitroarenes bearing electron-withdrawing $\left(-\mathrm{CF}_{3}\right)$ and electron-donating $(-\mathrm{OMe})$ substituents were both tolerated (entries 6-10). Nitro-groups were successfully reduced in the presence of aryl-chloride and fluoride substituents without protodehalogenation (entries 11-14), however, 4-bromo-nitrobenzene 50 was reduced to both 4-bromoaniline and to the proto-dehalogenated product aniline (entry 15).

Chemoselective nitro-group reduction was observed in the presence of ester and amide functionalities (entries 17-19). The synthesis of the analgesic benzocaine 6r from the corresponding nitroarene showcases the utility of this methodology. Perhaps unsurprisingly, a substrate bearing a ketone 5p showed poor chemoselectivity with the carbonyl being reduced in addition to the nitro-group (entry 16).

$p$-(Methylthio)-aniline 5t was successfully produced from the corresponding nitroarene in good yield (entry 20). The corresponding methylsulfonyl substituted nitroarene $\mathbf{5 u}$ was also successfully reduced, albeit with lower isolated yield (entry 21). 8-Nitroquinoline $5 \mathbf{w}$ was successfully reduced to 8 -aminoquinoline (entry 23). Interestingly, treatment of nitrosubstituted benzoxazole $\mathbf{5 x}$ and benzothiazole $5 \mathbf{y}$ derivatives with $\mathrm{NaBH}_{4}$ in the absence of an iron salt exclusively gave the reductively ring-opened product. However, in the presence of $\mathrm{Fe}(\mathrm{OTf})_{3}$, only the chemoselective reduction of the nitro-group was observed (entries 24 and 25). Aliphatic nitro-groups were also reduced by the $\mathrm{Fe}(\mathrm{OTf})_{3} / \mathrm{NaBH}_{4}$ system (entry 26), however increased loadings of both the catalyst and stoichiometric reductant were required.

Two contrasting mechanisms have been proposed for previously reported iron-catalysed, $\mathrm{NaBH}_{4}$-mediated, alkene reductions. We sought to gain insight into which of the following mechanisms is operating in our developed reaction conditions. Kano proposed the addition of an iron-hydride to the alkene, followed by proton abstraction from ethanol. ${ }^{11 a}$ In contrast, Boger proposed that both hydrogen atoms originated from sodium borohydride. ${ }^{12 a}$ Additionally, $\mathrm{NaBH}_{4}$ has been shown to reduce iron(II/III) salts to a range of nanoparticulate or low oxidation-state iron and iron/boron species. ${ }^{25,27}$ While the formation of nanoparticles cannot be ruled out, the lack of stabilisers or an induction period would appear to suggest against these being the active catalytic species. In order to investigate the origin of the added hydrogen, and gain insight into the mode of operation of the low-valent catalyst, a series of deuterium incorporation experiments were carried out.

Reduction of 4-phenyl-1-butene 1a using $\mathrm{NaBD}_{4}$ and $\mathrm{d}_{1}$-ethanol gave exclusively the dideuterated alkane $\mathrm{d}_{2}$-2a (Scheme 3a). In line with previous reports of deuterium exchange between $\mathrm{NaBD}_{4}$ and alcoholic solvents, ${ }^{28}$ performing the reduction with $\mathrm{NaBD}_{4}$ and ethanol gave a mixture of deuterated and non-deuterated alkanes (Scheme $3 \mathrm{~b}$ ). In both cases deuterium was incorporated in both $\mathrm{C} 3$ and $\mathrm{C} 4$ positions of 
Table 4 Scope and limitation of the iron-catalysed, hydride-mediated reduction ${ }^{a}$

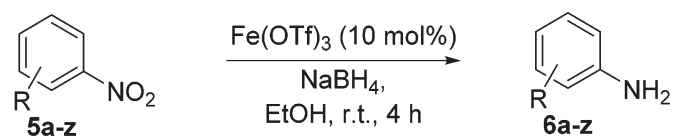

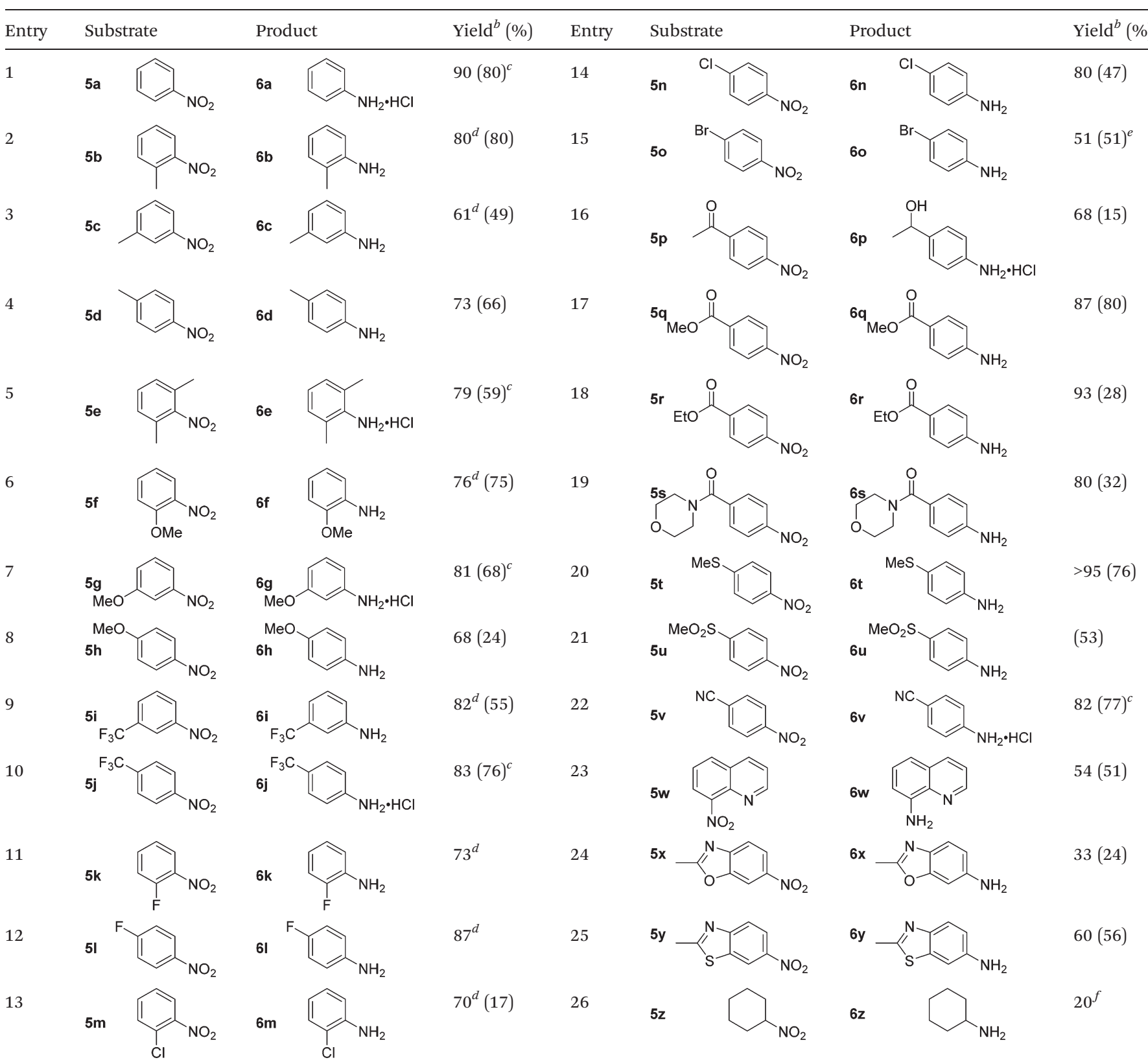

${ }^{a}$ Conditions: $0.5 \mathrm{mmol}$ nitroarene, $10 \mathrm{~mol} \%$ FeOTf 3 , EtOH $(4 \mathrm{ml}), 20$ equiv. $\mathrm{NaBH}_{4}$, r.t., 4 h. ${ }^{b}$ Yield determined by ${ }^{1} \mathrm{H}$ NMR using 1,3,5-trimethoxybenzene as internal standard. Isolated yield in parentheses. ${ }^{c}$ Isolated as the $\mathrm{HCl}$ salt. ${ }^{d}$ 1,2-Dichloroethane used as internal standard. ${ }^{e} 9 \%$ aniline also recovered. ${ }^{f}$ Conditions: 50 mol\% FeOTf 3,30 equiv. $\mathrm{NaBH}_{4}$.

the alkane. In order to probe the existence of a radial intermediate, $\mathrm{d}_{5}$-EtOH was used as the reaction solvent to probe radical abstraction from the $\mathrm{CD}_{2} \mathrm{OH}$ position, however, no deuterium incorporation was observed (Scheme 3c). This suggests an ionic, rather than radical mechanism.

\section{Conclusions}

In conclusion, a single, general, operationally simple and highly applicable protocol for the formal hydrogenation of apolar (alkene) and polar (nitro-) functionalities has been deve- 
a)

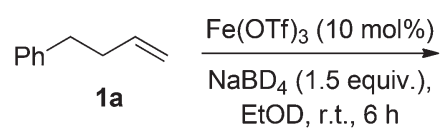

b)

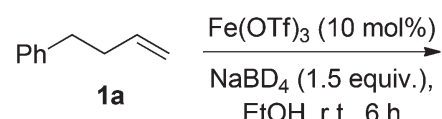

c)

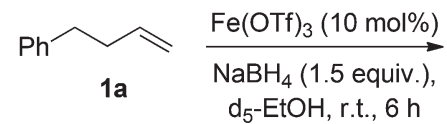

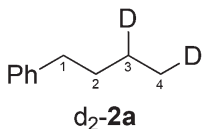

$2 a / d_{2}-2 a(1: 3)$

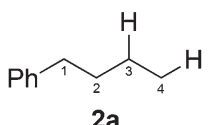

$2 a$<smiles>O=CC(CO)CCc1ccccc1</smiles>

Scheme 3 Deuterium labelling studies for the investigation of the mechanism of iron-catalysed, $\mathrm{NaBH}_{4}$ mediated, alkene reduction.

loped using a simple iron salt as catalyst. Using $\mathrm{Fe}(\mathrm{OTf})_{3}$ (10 mol\%) and $\mathrm{NaBH}_{4}$ as the stoichiometric reductant, a wide range of functionalised and unfunctionalised alkenes and aryland alky nitro-groups have been successfully hydrogenated under operationally simple, environmentally benign reaction conditions.

\section{Acknowledgements}

AJM thanks GlaxoSmithKline and the University of Edinburgh for the provision of a studentship. JEN thanks the Wellcome Trust, Nuffield Foundation and RSC for summer scholarships. SPT thanks the University of Edinburgh and GlaxoSmithKline for continued support. Additionally, we would like to thank MD Greenhalgh for the provision of substrates 1b, 1c, 1d, 1e, $\mathbf{1 g}$ and $\mathbf{1 h}$; and Dr D Best for substrates 5w, 5x, and $5 \mathbf{y}$.

\section{Notes and references}

1 (a) M. B. Smith, in Organic Synthesis, McGraw-Hill, Avenue of the Americas, New York, United States of America, 2nd edn, 2002; (b) Comprehensive Organic Synthesis, ed. P. Knochel and G. A. Molander, Elsevier, Amsterdam, Netherlands, 2nd edn, 2014, vol. 8; (c) The Handbook of Homogeneous Hydrogenation, ed. J. G. de Vries and C. J. Elsevier, Wiley-VCH Verlag GmbH \& Co. KGaA, Weinheim, Germany, 2007; (d) Handbook of Heterogeneous Catalytic Hydrogenation for Organic Synthesis, ed. S. Nishimura, John Wiley \& Sons, Inc., New York, United States of America, 2001.

2 (a) H. Sajiki and Y. Monguchi, in Pharmaceutical Process Chemistry, ed. T. Shioiri, K. Izawa and T. Konoike, WileyVCH Verlag GmbH \& Co. KGaA, Weinheim, Germany, 2010; (b) Handbook of Reagents for Organic Synthesis, Oxidising and Reducing Agents, ed. S. D. Burke and R. L. Danheiser, John Wiley \& Sons, Inc., New York, United States of America, 1999, vol. 2.

3 British Geological Survey Risk List 2012, retrieved 16/12/ 2013.
4 (a) R. M. Bullock, Science, 2013, 342, 1054; (b) S. Enthaler, K. Junge and M. Beller, Angew. Chem., Int. Ed., 2008, 47, 3317.

5 (a) W. M. Czaplik, M. Mayer, J. Cvengroš and A. Jacobi von Wangelin, ChemSusChem, 2009, 2, 396; (b) B. D. Sherry and A. Fürstner, Acc. Chem. Res., 2008, 41, 1500; (c) E. Nakamura and N. Yoshikai, J. Org. Chem., 2010, 75, 6061; (d) A. Correa, O. G. Mancheño and C. Bolm, Chem. Soc. Rev., 2008, 37, 1108.

6 (a) K. Junge, K. Schroder and M. Beller, Chem. Commun., 2011, 47, 4849; (b) B. A. F. Le Bailly and S. P. Thomas, $R S C$ Adv., 2011, 1, 1435; (c) M. D. Bhor, A. G. Panda, S. R. Jagtap and B. M. Bhanage, Catal. Lett., 2008, 124, 157; (d) P.-H. Phua, L. Lefort, J. A. F. Boogers, M. Tristany and J. G. de Vries, Chem. Commun., 2009, 3747; (e) S. Enthaler, M. Haberberger and E. Irran, Chem. - Asian J., 2011, 6, 1613; (f) R. Hudson, G. Hamasaka, T. Osako, Y. M. A. Yamada, C. J. Li, Y. Uozumi and A. Moores, Green Chem., 2013, 15, 2141; (g) A. Welther, M. Bauer, M. Mayer and A. Jacobi von Wangelin, ChemCatChem, 2012, 4, 1088.

7 (a) C. Bianchini, E. Farnetti, M. Graziani, M. Peruzzini and A. Polo, Organometallics, 1993, 12, 3753; (b) E. J. Daida and J. C. Peters, Inorg. Chem., 2004, 43, 7474; (c) B. A. F. Le Bailly, M. D. Greenhalgh and S. P. Thomas, Chem. Commun., 2012, 48, 1580; (d) T. S. Carter, L. Guiet, D. J. Frank, J. West and S. P. Thomas, Adv. Synth. Catal., 2013, 355, 880; (e) D. J. Frank, L. Guiet, A. Käslin, E. Murphy and S. P. Thomas, RSC Adv., 2013, 3, 25698.

8 (a) S. C. Bart, E. Lobkovsky and P. J. Chirik, J. Am. Chem. Soc., 2004, 126, 13794; (b) R. P. Yu, J. M. Darmon, J. M. Hoyt, G. W. Margulieux, Z. R. Turner and P. J. Chirik, ACS Catal., 2012, 2, 1760; (c) P. Chirik and K. Wieghardt, Science, 2010, 327, 794.

9 P. Rittmeyer and U. Wietelmann, in Ullmann's Encyclopedia of Industrial Chemistry, Wiley-VCH Verlag $\mathrm{GmbH} \& \mathrm{Co}$. KGaA, 2000.

10 (a) E. C. Ashby and J. J. Lin, Tetrahedron Lett., 1977, 18, 4481; (b) E. C. Ashby and J. J. Lin, J. Org. Chem., 1978, 43, 2567.

11 (a) K. Kano, M. Takeuchi, S. Hashimoto and Z. Yoshida, J. Chem. Soc., Chem. Commun., 1991, 1728; (b) M. Takeuchi and K. Kano, Organometallics, 1993, 12, 2059.

12 (a) H. Ishikawa, D. A. Colby, S. Seto, P. Va, A. Tam, H. Kakei, T. J. Rayl, I. Hwang and D. L. Boger, J. Am. Chem. Soc., 2009, 131, 4904; (b) E. K. Leggans, T. J. Barker, K. K. Duncan and D. L. Boger, Org. Lett., 2012, 14, 1428; (c) T. J. Barker and D. L. Boger, J. Am. Chem. Soc., 2012, 134, 13588.

13 R. S. Downing, P. J. Kunkeler and H. van Bekkum, Catal. Today, 1997, 37, 121.

14 (a) J. F. Knifton, J. Org. Chem., 1975, 40, 519; (b) J. F. Knifton, J. Org. Chem., 1976, 41, 1200; (c) K. Cann, T. Cole, W. Slegeir and R. Pettit, J. Am. Chem. Soc., 1978, 100, 3969; (d) F. Ragaini, J.-S. Song, D. L. Ramage, G. L. Geoffroy, G. A. P. Yap and A. L. Rheingold, Organo- 
metallics, 1995, 14, 387; (e) F. Ragaini, Organometallics, 1996, 15, 3572 .

15 (a) K. Junge, B. Wendt, N. Shaikh and M. Beller, Chem. Commun., 2010, 46, 1769; (b) G. Wienhofer, I. Sorribes, A. Boddien, F. Westerhaus, K. Junge, H. Junge, R. Llusar and M. Beller, J. Am. Chem. Soc., 2011, 133, 12875.

16 (a) R. V. Jagadeesh, G. Wienhöfer, F. A. Westerhaus, A.-E. Surkus, M. M. Pohl, H. Junge, K. Junge and M. Beller, Chem. Commun., 2011, 47, 10972; (b) R. V. Jagadeesh, A.-E. Surkus, H. Junge, M.-M. Pohl, J. Radnik, J. Rabeah, H. Huan, V. Schünemann, A. Brückner and M. Beller, Science, 2013, 342, 1073.

17 (a) A. K. Shil, D. Sharma, N. R. Guha and P. Das, Tetrahedron Lett., 2012, 53, 4858; (b) I. Pogorelić, M. Filipan-Litvić, S. Merkaš, G. Ljubić, I. Cepanec and M. Litvić, J. Mol. Catal. A: Chem., 2007, 274, 202; (c) D. Setamdideh, B. Khezri and M. Mollapour, Orient. J. Chem., 2011, 27, 991; (d) H. K. Kadam and S. G. Tilve, RSC Adv., 2012, 2, 6057.

18 (a) S. Sakaki, S. Mitarai and K. Ohkubo, Chem. Lett., 1991, 20, 195; (b) S. Sakaki, T. Kimura, T. Ogata, H. Hasuo and T. Arai, New J. Chem., 1994, 18, 231.

19 See ESI† for details.

20 (a) T. Taniguchi, N. Goto, A. Nishibata and H. Ishibashi, Org. Lett., 2010, 12, 112; (b) K. I. Booker-Milburn and D. F. Thompson, J. Chem. Soc., Perkin Trans. 1, 1995, 2315; (c) K. I. Booker-Milburn, A. Barker, W. Brailsford, B. Cox and T. E. Mansley, Tetrahedron, 1998, 54, 15321; (d) T. Bach, B. Schlummer and K. Harms, Chem. Commun.,
2000, 287; (e) K. I. Booker-Milburn, J. Leighton Jones, G. E. M. Sibley, R. Cox and J. Meadows, Org. Lett., 2003, 5, 1107.

$21 \mathrm{Fe}(\mathrm{OTf})_{3}$ gave complete reduction in less than 15 minutes, whereas $\mathrm{FeCl}_{3}$ required 90 minutes.

22 S. L. Buchwald and C. Bolm, Angew. Chem., Int. Ed., 2009, 48, 5586.

23 W. M. Czaplik, S. Grube, M. Mayer and A. Jacobi von Wangelin, Chem. Commun., 2010, 46, 6350.

24 (a) K. Soai, K. Komiya, Y. Shigematsu, H. Hasegawa and A. Ookawa, J. Chem. Soc., Chem. Commun., 1982, 1282; (b) K. Soai, H. Oyamada, M. Takase and A. Ookawa, Bull. Chem. Soc. Jpn., 1984, 57, 1948.

25 C. Rangheard, C. de Julian Fernandez, P.-H. Phua, J. Hoorn, L. Lefort and J. G. de Vries, Dalton Trans., 2010, 39, 8464 .

26 A second screen of iron salts using the conditions in Table 2; no simple iron salt/ $\mathrm{NaBH}_{4}$ system was found to be competent for the reduction of $\beta$-methyl styrene (Table S3 $\$$ ).

27 (a) G. N. Glavee, K. J. Klabunde, C. M. Sorensen and G. C. Hadjipanayis, Inorg. Chem., 1995, 34, 28; (b) A. Martino, M. Stoker, M. Hicks, C. H. Bartholomew, A. G. Sault and J. S. Kawola, Appl. Catal., A, 1997, 161, 235; (c) F. Li, C. Vipulanandan and K. K. Mohanty, Colloids Surf., A, 2003, 223, 103.

28 G. C. Lloyd-Jones and S. C. Stephen, Chem. - Eur. J., 1998, 4, 2539-2549. 